\title{
Serum fatty acid levels, dietary style and coronary heart disease in three neighbouring areas in Japan: the Kumihama study
}

\author{
Tomoki Nakamura $^{1,2} *$, Akihiro Azuma ${ }^{2}$, Toshiro Kuribayashi ${ }^{2}$, Hiroki Sugihara $^{2}$, Seisuke Okuda ${ }^{1}$ and \\ Masao Nakagawa ${ }^{2}$ \\ ${ }^{1}$ Department of Medicine, Kumihama Municipal Hospital, Kyoto, Japan \\ ${ }^{2}$ Second Department of Medicine, Kyoto Prefectural University of Medicine, Kyoto, Japan
}

(Received 16 July 2001 - Revised 9 May 2002 - Accepted 6 September 2002)

\begin{abstract}
CHD mortality is extremely low in Japan, particularly in rural districts, when compared with that in Western countries. This has been partly attributed to the difference in dietary lifestyle. We investigated the factors influencing CHD mortality in a rural coastal district of Japan, comprising mercantile, farming, and fishing areas with distinct dietary habits. We prospectively examined the incidence of CHD from 1994 to 1998, as well as coronary risk factors and serum fatty acid concentrations. The incidence of angina pectoris was significantly $(P=0 \cdot 01)$ lower in the fishing area than in the mercantile and farming areas. Blood pressure, physical activity, prevalence of diabetes, serum levels of uric acid and HDL-cholesterol were similar between the three areas. Total- and LDL-cholesterol levels were significantly lower but the smoking rate was markedly higher in the fishing area than in the other two areas. Serum levels of saturated fatty acids and $n-6$ polyunsaturated fatty acids (PUFA) were lowest in the fishing area, but $n-3$ PUFA did not differ significantly. The $n-6: n-3$ PUFA ratio was lowest and eicosapentaenoic:arachidonic acid was highest in the fishing area. Although many previous studies have emphasized the beneficial effect of $n$-3 PUFA in preventing CHD, the present study indicated that a lower intake of $n-6$ PUFA and saturated fatty acids has an additional preventive effect on CHD even when the serum level of $n-3$ PUFA is high because of high dietary fish consumption.
\end{abstract}

Coronary heart disease: Dietary style: Fatty acids: Coronary risk factors

The mortality from CHD in Japan is 22 to 26/100000 population per year (Fukiyama et al. 2000), which is very low in comparison with the United States and northern Europe (Crombie et al. 1987). A lower CHD mortality is also observed in Mediterranean Europe and France (Criqui \& Ringel, 1994). These regional differences are thought to be partly due to differences in dietary habits. The average dietary intake of fish in Japan is about five times that in the United States (Crombie et al. 1987). Wine and Mediterranean fish dishes have also been reported to reduce CHD mortality (Renaud \& de Lorgeril, 1992; Criqui \& Ringel, 1994; de Lorgeri et al. 1999). Recently, the incidence of CHD has been increasing in urban areas of Japan as westernization of the diet has become widespread, while that in rural areas still remains low (Konishi et al. 1987).

Kumihama town is a coastal rural community in Kyoto
Prefecture, facing the Sea of Japan with an area of $145.04 \mathrm{~km}^{2}$ and a population of 12584 in the 1995 census. Kumihama town contains mercantile, farming, and fishing areas. The inhabitants in the mercantile area are mostly the owners of small shops and their families. The population and mean age in each area are: 2069 and 45 years in the mercantile area, 7571 and 45 years in the farming area, and 2944 and 46 years in the fishing area. The inhabitants of the three areas, each with similar incomes and educational backgrounds, move rarely from one area to another. Since Kumihama Municipal Hospital is the only institution in the district with a coronary care unit for intervention and there are no cardiologists in other hospitals, all the patients with CHD in Kumihama town were referred to and treated at this hospital.

In routine clinical practice, we had noticed that patients with CHD were few in the fishing area. The analysis of

\footnotetext{
Abbreviations: AA, arachidonic acid; AMI, acute myocardial infarction; AP, angina pectoris; EPA, eicosapentaenoic acid; PUFA, polyunsaturated fatty acids; SFA, saturated fatty acids.

*Corresponding author: Dr Tomoki Nakamura, fax +81 75251 5514, email tomnak@koto.kpu-m.ac.jp
} 
such a regional difference within a small town may confirm the presence of a relationship between CHD and dietary lifestyle, the relationship having been suggested in many reports covering study populations from distant districts or different countries with various environmental and genetic conditions. Therefore, we performed a cross-sectional, prospective survey to analyse the relationship between CHD incidence and lifestyle of the inhabitants of the three neighbouring areas in Kumihama town.

\section{Subjects and methods}

The present study, conducted between 1994 and 1998, consisted of two parts. First, CHD incidence was analysed to confirm our notion that the incidence of CHD is low in the fishing area. Second, serum fatty acids levels and lifestyles were examined in apparently healthy subjects who participated in the annual health check in June 1998.

\section{Analysis of coronary heart disease incidence}

We studied patients from April 1994 to March 1998, who came to our hospital because of initial onset of chest pain or electrocardiographic abnormalities detected at the annual health check. Patients having past history of CHD were excluded from the present study. The diagnosis of angina pectoris (AP) was based on the exercise electrocardiography test using the Bruce protocol, and a positive electrocardiographic finding was defined as ischaemic ST segment depression $\geq 1 \mathrm{~mm}$. However, its diagnostic accuracy is relatively low (60-65\%). In order to exclude falsepositive electrocardiographic results, coronary angiography was performed, to which the subjects consented. Acute myocardial infarction (AMI) was diagnosed on the basis of chest pain lasting $>20$ min with ST elevation and an increase in the plasma creatinine phosphokinase level to more than twice the upper limit of normal. Of 100 patients with a positive exercise test, seventy-two gave consent to coronary angiography. Significant coronary stenosis was defined as $\geq 75 \%$ luminal narrowing (American Heart Association Committee, 1975).

\section{Annual health check}

The public health office of Kumihama town sent personal invitations for the annual health check to all inhabitants $\geq 40$ years by mail. The invitation also mentioned that individuals who were regularly visiting the hospital did not need take the examination. Thus, 2996 out of 7438 individuals $(40.3 \%)$ participated in this examination. The rate of response was: $45.1 \%$ in the mercantile; $38.0 \%$ in the farming; $43.3 \%$ in the fishing area. Because a large number of subjects were surveyed, the health check was held in June and October every year. Thus, we selected 1344 participants (389 in the mercantile, 587 in the farming, and 368 in the fishing area) of the June 1998 health check to exclude the possible influence of the seasonal difference in diet on serum fatty acid levels.

We used a quasi-random sampling frame in which we approached every $n$th apparently healthy subjects from the age-sex registers. A total of 294 individuals consented to the present study. The number of participants in each area was: ninety-five (thirty-eight men, fifty-seven women) in the mercantile, 118 (forty-seven men, seventyone women) in the farming, and eighty-one (thirty-two men, forty-nine women) in the fishing area, with no regional difference in the sampling of population $(P=0 \cdot 28)$. To obtain uniform information, experienced public health nurses carried out an interview using a questionnaire for the assessment of medical history, smoking habits, diet and physical activity. Diet was evaluated on the basis of weekly frequency of the intake of meat, fish, and vegetables using a recall method for the past week. Physical activity was estimated by using the Framingham Study questionnaire (Kannel \& Sorlie, 1979) and physical activity index was calculated from the weighted sum of hours spent at five levels of activity during a normal working day. Height was measured in stocking feet with an anthropometer in the upright position. Body weight was recorded by a weighing machine with the subjects clothed and $0.5 \mathrm{~kg}$ was subtracted from the recorded weight. Blood pressure was measured with a fully automated sphygmomanometer on the right arm with the subject in the sitting position after $5 \mathrm{~min}$ of rest, and calculated as the mean value of two serial measurements. Diabetes mellitus was defined by a plasma fasting blood glucose level $\geq 6.99 \mathrm{nmol} / \mathrm{l}$ plus a haemoglobin A1c value $\geq 6.5 \%$, according to the guidelines of the Japanese Diabetes Society.

Blood samples were taken from an antecubital vein after overnight fasting and were centrifuged at $3000 \mathrm{~g}$ for $15 \mathrm{~min}$ at room temperature. Then the serum was stored at $-80^{\circ} \mathrm{C}$ until assay. Total cholesterol and triacylglycerol were measured by enzymic methods. HDL-cholesterol was analysed by the phosphotungstate precipitation method (Wako, Osaka, Japan). The LDL-cholesterol level was calculated from the following formula: LDL cholesterol $=$ total cholesterol - HDL cholesterol - triacylglycerol/5 (Friedewald et al. 1972). Serum uric acid levels were determined by an enzymic method (Kyowa Medics, Tokyo, Japan).

\section{Analysis of serum fatty acids}

For the analysis of serum fatty acids, a reference mixture of fatty acid methyl esters (GLC-87) containing the internal standard, methyl heptadecanoate, was purchased from NU-Check-Prep, Inc., Elysian, MN, USA. Standards for methyl esters of eicosapentaenoic acid (EPA), docosapentaenoic acid (Nacalai Tesque, Inc., Kyoto, Japan), eicosadienoic acid, docosatetraenoic acid, lignoceric acid (NUCheck-Prep, Inc.), and 5-8-11 eicosatrienoic acid (Biomol Research Lab., Inc., Plymouth Meeting, PA, USA) were also added to the above reference mixture, and then the mixture was dissolved in $n$-hexane. Serum $(100 \mu \mathrm{l})$ was first extracted with $1 \mathrm{M}-\mathrm{KOH}$-ethanol in the presence of the internal standard at $60^{\circ} \mathrm{C}$ for $60 \mathrm{~min}$. After removing non-saponified fractions in $n$-hexane, the fatty acids were extracted in $n$-hexane-diethyl ether, methylated using diazomethane, and subjected to quantification by GC (Hewlett Packard GC system HP 6890; Palo Alto, CA, USA) with flame ionization detector (supplied with air 
and high-purity $\left.\mathrm{H}_{2}\right)$. A portion $(4 \mu \mathrm{l})$ was injected into a $30 \mathrm{~m}$ BP5 fused silica capillary column with an internal diameter of $250 \mu \mathrm{m}, 0.2 \mu \mathrm{m}$ thick film and a split ratio of $1: 26$. High purity $\mathrm{He}$ was used as the carrier gas $(1.8 \mathrm{ml} / \mathrm{min})$ and $\mathrm{N}_{2}$ was used as the make-up gas $(25 \mathrm{ml} /$ min). The initial oven temperature was $120^{\circ} \mathrm{C}$, followed by temperature programming in three steps: a first rate of $2^{\circ} \mathrm{C} / \mathrm{min}$ up to $170^{\circ} \mathrm{C}$, followed by a second rate of $1^{\circ} \mathrm{C} /$ min up to $200^{\circ} \mathrm{C}$ and by a third rate of $2^{\circ} \mathrm{C} / \mathrm{min}$ up to $230^{\circ} \mathrm{C}$, which was maintained for $10 \mathrm{~min}$. The injector and flame ionization detector temperatures were maintained at $250^{\circ} \mathrm{C}$ and $260^{\circ} \mathrm{C}$, respectively. Peaks were identified by comparison with known pure standard mixtures and quantified by automatic integration of areas. The results were expressed in absolute concentrations $(\mathrm{mg} / \mathrm{l}$ serum), using an internal standard.

\section{Statistical analysis}

Results are expressed as mean values and standard deviations. One-way ANOVA was used for parametric comparisons and significances of individual differences were evaluated by using Scheffe's test if ANOVA was significant. The $\chi^{2}$ test was applied for discrete variables. In order to investigate whether linoleic acid levels differ between the three areas, we conducted analysis of covariance, with LDL-cholesterol levels as a covariant. Statistical significance was defined as $P<0 \cdot 05$.

\section{Results}

\section{Distribution of coronary heart disease patients in the mercantile, farming and fishing areas}

There were no significant differences in the percentage of outpatients attending our hospital or in the rate of participation in the annual health checks between the three areas. The proportion of positive stress electrocardiograms was far lower in the fishing area. There were twelve AMI patients (two in the mercantile, nine in the farming and one in the fishing area) and thirty AP patients (nine in the mercantile, twenty in the farming and one in the fishing area). The overall incidence of AMI and AP (/100000 population per year) in Kumihama town was 24 and 60, which were only one-third and one-sixth of the average in Japan, respectively (Ito, 1987). Incidence of AMI did not differ significantly between the three areas, but that of AP was far lower in the fishing area (Table 1). We also assessed death certificates between 1994 and 1998, but no cases were observed of death by a cardiac cause.

\section{Clinical features, diet and smoking habits in the three areas}

There were no significant differences between the three areas with regard to gender, age, height, weight, BMI, physical activity index, mean blood pressure, fasting blood glucose, rate of diabetes and serum uric acid concentration. The serum levels of total cholesterol and LDLcholesterol were lower in subjects from the fishing area than in those from the mercantile area $(P<0.001$ for total cholesterol and $P<0.05$ for LDL-cholesterol), although the levels of HDL-cholesterol and triacylglycerol did not differ significantly.

The weekly frequency of meat intake was significantly $(P<0.0001)$ lower in the fishing area $(2.6(\mathrm{SD} 1.0))$ than in the mercantile area $(3.3$ (SD 1.0)) or the farming area $(3.2(\mathrm{SD} 1 \cdot 0))$. In contrast, the weekly frequency of fish intake was significantly $(P<0 \cdot 0001)$ higher in the fishing area $(5.2(\mathrm{SD} 1.3))$ than in the mercantile area $(3.2$ (SD $1.3))$ or the farming area $(2.7$ (SD 1.0)). Vegetables were eaten significantly $(P<0.0001)$ more frequently in the farming area $(4.4(\mathrm{SD} \mathrm{1.1)})$ than in the mercantile area (3.5 (SD 0.8)) or the fishing area (3.9 (SD 1.0)). The prevalence of smoking was markedly higher in the fishing area than in the other areas $(P=0 \cdot 01)$ (Table 2).

\section{Serum fatty acid levels in healthy inhabitants from the three areas}

Data on serum fatty acid levels obtained from the participants of the annual health check are presented in Table 3. Levels of saturated fatty acids (SFA, i.e. myristic acid, palmitic acid and stearic acid) were all significantly lower in the fishing area. Among monounsaturated fatty acids, palmitoleic acid did not differ between the three areas, but the level of oleic acid was significantly lower in the fishing area. With regard to $n-3$ polyunsaturated fatty acids (PUFA), there were no differences of EPA, docosapentaenoic acid, or docosahexaenoic acid between the three areas, although EPA levels tended to be higher in the fishing area. In contrast, $n-6$ PUFA levels (i.e. linoleic acid, $\gamma$-linolenic acid, dihomo- $\gamma$-linolenic acid and arachidonic acid (AA) were significantly lower in the fishing area. By analysis of covariance with LDL-cholesterol as a covariant, linoleic acid levels showed significant regional difference $(P<0 \cdot 0001)$. The $n-6: n-3$ PUFA ratio was lowest and EPA:AA highest in the fishing area $(P<0.0001$ and $P=0 \cdot 0001$, respectively).

Table 1. Population, positive stress electrocardiograms (ECG), and incidence of acute myocardial infarction (AMI) and angina pectoris $(\mathrm{AP})$ in each area

\begin{tabular}{lcrrr}
\hline & Mercantile area & Farming area & Fishing area & $P$ value \\
\hline Population & 2069 & 7571 & 2944 & \\
Positive stress ECG (/100 000 population per year) & 290 & 238 & 34 & $<0.0001$ \\
Incidence of AMI (/100 000 population per year) & 24 & 30 & 8 & 0.45 \\
Incidence of AP (/100 000 population per year) & 109 & 66 & 8 & 0.01 \\
\hline
\end{tabular}


Table 2. Clinical characteristics of the participants in annual medical screening from each area† (Mean values and standard deviations)

\begin{tabular}{|c|c|c|c|c|c|c|c|}
\hline & \multicolumn{2}{|c|}{ Mercantile area $(n 95)$} & \multicolumn{2}{|c|}{ Farming area $(n 118)$} & \multicolumn{2}{|c|}{ Fishing area $(n 81)$} & \multirow[b]{2}{*}{$P$ value } \\
\hline & Mean & SD & Mean & SD & Mean & SD & \\
\hline \multicolumn{8}{|l|}{ Gender } \\
\hline Male & \multirow{2}{*}{\multicolumn{2}{|c|}{$\begin{array}{l}38 \\
57\end{array}$}} & \multirow{2}{*}{\multicolumn{2}{|c|}{$\begin{array}{l}47 \\
71\end{array}$}} & \multicolumn{2}{|c|}{32} & \multirow[t]{2}{*}{$>0.99$} \\
\hline Female & & & & & & & \\
\hline Age (years) & 60 & 12 & 60 & 11 & 59 & 11 & 0.72 \\
\hline Height $(\mathrm{cm})$ & 156 & 9 & 155 & 8 & 158 & 9 & 0.19 \\
\hline Weight (kg) & 54 & 9 & 53 & 9 & 57 & 10 & 0.06 \\
\hline BMI $\left(\mathrm{kg} / \mathrm{m}^{2}\right)$ & 22 & 3 & 22 & 3 & 23 & 3 & 0.09 \\
\hline Physical activity index & 31 & 7 & 34 & 9 & 33 & 8 & $0 \cdot 10$ \\
\hline Mean blood pressure $(\mathrm{mmHg})$ & 98 & 13 & 100 & 14 & 96 & 13 & 0.11 \\
\hline Fasting blood glucose $(\mathrm{mmol} / \mathrm{l})$ & 5.05 & 1.44 & 4.83 & 0.78 & 4.77 & 0.72 & 0.46 \\
\hline Diabetic patients $(n)$ & \multicolumn{2}{|c|}{1} & \multicolumn{2}{|c|}{1} & \multicolumn{2}{|c|}{0} & 0.67 \\
\hline Uric acid $(\mathrm{mmol} / \mathrm{l})$ & 0.29 & 0.08 & 0.29 & 0.08 & 0.32 & 0.08 & 0.06 \\
\hline Total cholesterol (mmol/l) & 5.62 & 0.93 & $5 \cdot 36$ & 0.88 & $5 \cdot 13^{\star \star}$ & 0.70 & 0.0006 \\
\hline LDL-cholesterol (mmol/l) & 3.47 & 0.85 & $3 \cdot 21$ & 0.78 & $3 \cdot 13^{\star}$ & 0.60 & 0.01 \\
\hline HDL-cholesterol (mmol/II) & 1.63 & 0.36 & 1.66 & 0.36 & 1.55 & 0.34 & 0.08 \\
\hline Triacylglycerol $(\mathrm{mmol} / \mathrm{l})$ & 1.19 & 0.57 & $1 \cdot 13$ & 1.02 & 0.93 & 0.46 & 0.07 \\
\hline Smoking rate $(\%)$ & \multicolumn{2}{|c|}{11.6} & \multicolumn{2}{|c|}{16.9} & \multicolumn{2}{|c|}{28.4} & 0.01 \\
\hline
\end{tabular}

Mean values were significantly different from those of the mercantile area by Scheffe's test: ${ }^{\star} P<0.05,{ }^{\star \star} P<0.001$.

†For details of participants and procedures, see p. 268.

\section{Discussion}

The present study demonstrated that the incidence of CHD in a coastal rural district with three distinct populations was extremely low, as compared with the average of Japan (Ito, 1987). In particular, the incidence of CHD was lowest in the fishing area, where the frequency of fish consumption was much higher than that of meat consumption. Similar

Table 3. Serum fatty acid levels $(\mathrm{mg} / \mathrm{l})$ of the normal inhabitants of Kumihama town‡

(Mean values and standard deviations)

\begin{tabular}{|c|c|c|c|c|c|c|c|}
\hline & \multicolumn{2}{|c|}{$\begin{array}{l}\text { Mercantile area } \\
\quad(n 95)\end{array}$} & \multicolumn{2}{|c|}{$\begin{array}{l}\text { Farming area } \\
\quad(n 118)\end{array}$} & \multicolumn{2}{|c|}{$\begin{array}{l}\text { Fishing area } \\
(n 81)\end{array}$} & \multirow[b]{2}{*}{$P$ value } \\
\hline & Mean & SD & Mean & SD & Mean & SD & \\
\hline Lauric $(12: 0)$ & $3 \cdot 6$ & $3 \cdot 1$ & 3.0 & $2 \cdot 3$ & $1 \cdot 9^{\star \star \star \star \star \star} \dagger \dagger$ & $1 \cdot 1$ & $<0.0001$ \\
\hline Myristic (14:0) & $23 \cdot 0$ & $12 \cdot 0$ & $22 \cdot 7$ & 13.9 & $16 \cdot 4^{\star \star \star \star}+\dagger \dagger$ & 6.5 & 0.0001 \\
\hline Myristoleic (14:1n-5) & 1.7 & $1 \cdot 1$ & 1.6 & 0.9 & $1.4^{\star}$ & 0.5 & 0.01 \\
\hline Palmitic $(16: 0)$ & $646 \cdot 7$ & $146 \cdot 0$ & $658 \cdot 1$ & 227.9 & $548 \cdot 0^{\star \star \star}+† \dagger \dagger$ & $115 \cdot 9$ & $<0.0001$ \\
\hline Palmitoleic $(16: 1 n-7)$ & 83.7 & $34 \cdot 6$ & 83.8 & 44.1 & 73.6 & 29.6 & 0.12 \\
\hline Stearic $(18: 0)$ & $217 \cdot 3$ & $32 \cdot 0$ & $246 \cdot 3$ & $66 \cdot 4$ & $198 \cdot 3^{*}+\dagger † \dagger \dagger$ & 37.6 & $<0.0001$ \\
\hline Oleic $(18: 1 n-9)$ & 575.5 & $137 \cdot 0$ & $570 \cdot 1$ & $242 \cdot 8$ & $485 \cdot 7^{\star *}+\dagger$ & $118 \cdot 0$ & 0.0016 \\
\hline Linoleic $(18: 2 n-6)$ & 857.9 & $139 \cdot 2$ & $823 \cdot 0$ & $201 \cdot 6$ & $690 \cdot 4^{\star \star \star \star \star \star}+† \dagger † \dagger$ & 149.5 & $<0.0001$ \\
\hline$\alpha$-Linolenic $(18: 3 n-3)$ & 21.5 & $6 \cdot 7$ & $20 \cdot 5$ & $9 \cdot 3$ & $17 \cdot 3^{\star \star \star} \dagger$ & $6 \cdot 1$ & 0.0012 \\
\hline$\gamma$-Linolenic $(18: 3 n-6)$ & $9 \cdot 7$ & $5 \cdot 7$ & $11 \cdot 3$ & $7 \cdot 4$ & $8.4 \dagger \dagger$ & $5 \cdot 5$ & 0.006 \\
\hline Arachidic $(20: 0)$ & $2 \cdot 2$ & 0.7 & $3 \cdot 4^{\star \star \star \star \star *}$ & 1.1 & $3 \cdot 2^{\star \star \star \star \star \star *}$ & $1 \cdot 1$ & $<0.0001$ \\
\hline Eicosenoic $(20: 1 n-9)$ & $6 \cdot 7$ & 1.5 & $6 \cdot 5$ & $2 \cdot 6$ & $5 \cdot 8^{*} \dagger$ & 1.7 & 0.006 \\
\hline Eicosadienoic $(20: 2 n-6)$ & 6.5 & $2 \cdot 4$ & $5 \cdot 8^{\star}$ & 1.9 & $5 \cdot 0^{\star \star \star \star \star \star \star}+\dagger$ & 1.3 & $<0.0001$ \\
\hline Dihomo- $\gamma$-linolenic $(20: 3 n-6)$ & $35 \cdot 1$ & $11 \cdot 0$ & $36 \cdot 7$ & 11.4 & 30.9††† - - l - l & $12 \cdot 6$ & 0.0026 \\
\hline 5-8-11 Eicosatrienoic $(20: 3 n-9)$ & $2 \cdot 0$ & 1.0 & $2 \cdot 4$ & $2 \cdot 2$ & 1.9 & $1 \cdot 3$ & 0.06 \\
\hline Arachidonic $(20: 4 n-6)$ & 154.9 & $26 \cdot 0$ & $142 \cdot 3^{\star \star}$ & 33.0 & $130 \cdot 6^{\star * \star \star \star \star} \dagger$ & 27.9 & $<0.0001$ \\
\hline Eicosapentaenoic $(20: 5 n-3)$ & 89.5 & $39 \cdot 6$ & 83.6 & 35.5 & 96.9 & $46 \cdot 2$ & 0.07 \\
\hline Behenic $(22: 0)$ & $7 \cdot 1$ & 4.0 & $8 \cdot 0$ & 4.8 & 5.6 & 2.5 & 0.0003 \\
\hline Erucic $(22: 1 n-9)$ & $2 \cdot 2$ & $2 \cdot 0$ & $2 \cdot 4$ & 1.6 & $2 \cdot 2$ & $1 \cdot 3$ & 0.64 \\
\hline Docosatetraenoic (22: 4n-6) & $2 \cdot 8$ & 0.7 & $2 \cdot 4^{\star \star \star}$ & 0.9 & $2 \cdot 1^{\star \star \star \star * *}$ & $1 \cdot 1$ & $<0.0001$ \\
\hline Docosapentaenoic (22:5n-3) & $33 \cdot 0$ & $9 \cdot 7$ & $33 \cdot 1$ & 11.5 & $32 \cdot 6$ & $20 \cdot 3$ & 0.96 \\
\hline Docosahexaenoic $(22: 6 n-3)$ & $188 \cdot 1$ & $50 \cdot 0$ & $174 \cdot 8$ & $53 \cdot 3$ & 174.5 & $60 \cdot 7$ & 0.14 \\
\hline Lignoceric $(24: 0)$ & $1 \cdot 7$ & 0.7 & $2 \cdot 0$ & $1 \cdot 2$ & $1.6 \dagger$ & 0.9 & 0.02 \\
\hline Nervonic $(24: 1 n-9)$ & $2 \cdot 6$ & 2.4 & $4 \cdot 0^{* *}$ & $2 \cdot 1$ & $4 \cdot 5^{\star \star \star \star}$ & 4.7 & 0.0002 \\
\hline$n-6: n-3$ Polyunsaturated fatty acid ratio & 3.44 & 0.97 & 3.57 & $1 \cdot 30$ & $3 \cdot 07^{\star \star * \star \star}+† \dagger \dagger$ & 1.29 & $<0.0001$ \\
\hline Eicosapentaenoic acid:arachidonic acid & 0.58 & 0.23 & 0.60 & 0.27 & $0 \cdot 74^{\star * * \star \star}+\dagger \dagger$ & 0.31 & 0.0001 \\
\hline
\end{tabular}

Mean values were significantly different from those of the mercantile area by Scheffe's test: ${ }^{\star} P<0 \cdot 05,{ }^{\star \star} P<0.01,{ }^{\star \star \star} P<0 \cdot 005$, ${ }^{\star \star \star \star} P<0 \cdot 001$, ${ }^{\star \star \star \star \star} P<0.0005$, $\star \star \star \star \star \star P<0.0001$.

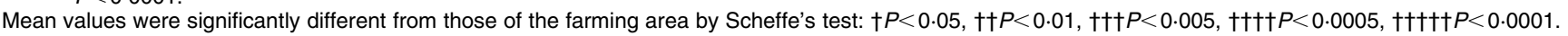
†For details of participants and procedure see p. 268. 
Table 4. Serum eicosapentaenoic acid:arachidonic acid reported in Japan

\begin{tabular}{|c|c|c|c|c|}
\hline \multirow[b]{2}{*}{ Investigators } & \multicolumn{4}{|c|}{ Area } \\
\hline & Rural mercantile & Farming & Fishing & Urban \\
\hline Hirai et al. (1986) & & & 0.58 & \\
\hline Iso et al. (1989) & & 0.77 & & 0.45 \\
\hline Shiba et al. (1980) & & 0.34 & 0.68 & \\
\hline Kamada et al. (1991) & & 0.57 & 0.59 & \\
\hline Nakamura et al. (2002) (Present study) & 0.58 & 0.60 & 0.74 & \\
\hline
\end{tabular}

results have already been obtained in previous studies on native Greenlanders and Japanese (Dyerberg et al. 1975; Dyerberg \& Bang, 1979; Hirai et al. 1980; Hirai, 1985). There were no differences between the three areas in the incidence of hypertension, diabetes, hyperuricaemia and low HDL-cholesterol, which are widely accepted coronary risk factors (Gordon et al. 1977). Physical activity did not differ either, despite its beneficial effect on CHD (Andersen et al. 1999; Dunn et al. 1999; Hambrecht et al. 2000). In the fishing area, however, total cholesterol level was lowest but smoking rate was highest. In native Greenlanders also, CHD mortality is extremely low despite their highly prevalent smoking habits (Bjerregaard et al. 1997).

The $n-6: n-3$ PUFA ratio was lowest and EPA:AA highest in the fishing area. The high EPA:AA in the fishing area may be attributable to a low AA level, since EPA levels did not differ statistically between the three areas. The $n-6: n-3$ PUFA ratio reflects the consumption balance between fats of terrestrial and marine origin, and the ratio was negatively correlated with CHD mortality (Dolecek \& Grandits, 1991). In addition to a low dietary EPA:AA, a high dietary n-6:n-3 PUFA ratio, rather than a high serum cholesterol level, has also been reported to be a major risk factor for CHD (Kondo et al. 1986; Okuyama, 2001). These results suggest that the component of dietary fats is more important than the current coronary risk factors.

In the present study, we measured all twenty-four fractions of serum fatty acids but did not quantify dietary fat intake. It has been reported, however, that serum fatty acid levels change in parallel with the amount of dietary fats taken for the past $7 \mathrm{~d}$ (Kuriki et al. 2000) although the washout and half-lives vary with fatty acids to some extent (Zuijdgeest-van Leeuwen et al. 1999). Thus we may safely consider that serum fatty acid levels reliably reflect the dietary style.

All SFA and $n-6$ PUFA showed lower levels in the fishing area, but $n-3$ PUFA levels, except $\alpha$-linolenic acid, did not differ between the three areas. EPA:AA in each area of Kumihama town was higher than the reported ratio in other rural districts (Table 4, Hirai et al. 1980; Shiba et al. 1980; Iso et al. 1989; Kamada et al. 1991) despite similar n-3 PUFA levels, which suggests that fish consumption was relatively high even in the mercantile and farming areas, probably because of their location adjacent to the fishing area. The level of $\alpha$-linolenic acid, the precursor of EPA, was low in the fishing area, as has been found in other studies (Iso et al. 1989; Umemura et al. 1993). This may reflect the fact that $\alpha$-linolenic acid is abundant in vegetables and soyabeans and that its intake does not solely depend on fish consumption.
It has been reported that SFA intake is positively correlated with the serum total cholesterol level and CHD mortality (Keys, 1970; Keys et al. 1986). Several studies have found no relationship between $n$ - 6 PUFA intake and CHD mortality (Keys, 1970; Morris et al. 1977; Dolecek \& Grandits, 1991), but excessive intake of linolenic acid was reported to increase CHD mortality (Taylor et al. 1979). In the present study, linolenic acid level was lowest in the fishing area, which was independent of serum LDL-cholesterol levels. Since the serum level of $n-3$ PUFA did not differ between the three areas, the low incidence of CHD in the fishing area may have been related to the lower levels of SFA and $n-6$ PUFA, which may have partly contributed to the suppression of total cholesterol level.

We did not evaluate serum levels of homocysteine, folic acid and vitamins $\mathrm{B}_{6}$ and $\mathrm{B}_{12}$. Elevated homocysteine levels were recently reported to be related to the increase of cardiovascular risk (Duell \& Malinow, 1997), and levels can be lowered by supplementation with folic acid, vitamins $\mathrm{B}_{6}$ and $\mathrm{B}_{12}$ (Malinow et al. 1998; Rimm et al. 1998). However, homocysteine levels are not affected by dietary fat contents (Grundt et al. 1999). Thus, these levels are not considered to have influenced our results greatly.

Many previous studies have emphasized the beneficial effect of $n$-3 PUFA in preventing CHD, but there have been few studies suggesting that a low $n-6$ PUFA intake is useful in this respect. However, the present study indicated that a lower intake of $n-6$ PUFA and SFA has an additional preventive effect on CHD even when the serum level of $n-3$ PUFA is high because of high dietary fish consumption.

\section{Acknowledgements}

The authors would like to thank Tomohito Hamazaki (Toyama Medical and Pharmaceutical University, Toyama, Japan) for invaluable suggestions and Chieko Okuda (Louis Pasteur Center for Medical Research, Kyoto, Japan) for helpful suggestions in statistical analyses. Also, we are grateful to Tohru Adachi, Takashi Wada, Shinji Matsuda, and Tsutomu Takemura for their support in the analysis of fatty acids.

\section{References}

American Heart Association Committee (1975) AHA Committee Report: A reporting system on patient evaluated for coronary 
artery disease. News from the American Heart Association. Circulation 51, 5.

Andersen RE, Wadden TA, Bartlett SJ, Zemel B, Verde TJ \& Franckowiak AC (1999) Effects of lifestyle activity vs structured aerobic exercise in obese women: a randomized trial. Journal of the American Medical Association 281, 335-340.

Bjerregaard P, Mulvad G \& Pedersen HS (1997) Cardiovascular risk factors in Inuit of Greenland. International Journal of Epidemiology 26, 1182-1190.

Criqui MH \& Ringel BL (1994) Does diet or alcohol explain the French paradox? Lancet 344, 1719-1723.

Crombie IK, McLoone P, Smith WCS, Thomson M \& Pedoe HT (1987) International differences in coronary heart disease mortality and consumption of fish and other foodstuffs. European Heart Journal 8, 560-563.

de Lorgeril M, Salen P, Martin JL, Monjaud I, Delaye J \& Mamelle N (1999) Mediterranean diet, traditional risk factors, and the rate of cardiovascular complications after myocardial infarction. Final report of the Lyon diet heart study. Circulation 99, 779-785.

Dolecek TA \& Grandits G (1991) Dietary polyunsaturated fatty acids and mortality in the multiple risk factor intervention trial (MRFIT). World Review of Nutrition and Diet 66, 205-216.

Duell PB \& Malinow MR (1997) Homocyst(e)ine: an important risk factor for atherosclerotic vascular disease. Current Opinion in Lipidology 8, 28-34.

Dunn AL, Marcus BH, Kampert JB, Garcia ME, Kohl HW III \& Blair SN (1999) Comparison of lifestyle and structured interventions to increase physical activity and cardiorespiratory fitness: a randomized trial. Journal of the American Medical Association 281, 327-334.

Dyerberg J \& Bang HO (1979) Haemostatic function and platelet polyunsaturated fatty acids in Eskimos. Lancet ii, 433-435.

Dyerberg J, Bang HO \& Hjorne N (1975) Fatty acid composition of the plasma lipids in Greenland Eskimos. American Journal of Clinical Nutrition 28, 958-966.

Friedewald WT, Levy RI \& Fredrickson DS (1972) Estimation of the concentration of low-density lipoprotein cholesterol in plasma, without use of the preparative ultracentrifuge. Clinical Chemistry 18, 499-502.

Fukiyama K, Kimura Y \& Muratani H (2000) Incidence and longterm prognosis of initial stroke and acute myocardial infarction in Okinawa, Japan. Hypertension Research 23, 127-135.

Gordon T, Castelli WP, Hjortland MC, Kannel WB \& Dawber TR (1977) High density lipoprotein as a protective factor against coronary heart disease. The Framingham study. American Journal of Medicine 62, 707-714.

Grundt H, Nilsen DW, Hetland O, Mansoor MA, Aarsland T \& Woie L (1999) Atherothrombogenic risk modulation by $n-3$ fatty acids was not associated with changes in homocysteine in subjects with combined hyperlipidemia. Thrombosis and Haemostasis 81, 561-565.

Hambrecht R, Wolf A, Gielen S, Linke A, Hofer J, Erbs S, Schoene N \& Schuler G (2000) Effect of exercise on coronary endothelial function in patients with coronary artery disease. New England Journal of Medicine 342, 454-460.

Hirai A (1985) An epidemiological study on the dietary ingestion of eicosapentaenoic acid (EPA) and platelet function in Japanese. Journal of the Japanese Society of Internal Medicine 74, 13-20 (in Japanese).

Hirai A, Hamazaki T, Tateno T, Nishikawa T, Tamura Y \& Kumagai A (1980) Eicosapentaenoic acid and platelet function in Japanese. Lancet ii, 1132-1133.

Iso H, Sato S, Falsom AR, Shimamoto T, Terao A, Munger RG, Kitamura A, Konishi M, Iida M \& Komachi Y (1989) Serum fatty acids and fish intake in rural Japanese, urban Japanese,
Japanese American and Caucasian American men. International Journal of Epidemiology 18, 374-381.

Ito Y (1987) Epidemiology of coronary artery disease in Japan. In Coronary Artery Disease, vol. 45, pp. 1096-1102. Osaka, Japan: Nihon Rinsyo Inc. (in Japanese).

Kamada I, Tsutsui T, Chatani Y, Hifumi J, Ohfuji M, Adachi T \& Ohta H (1991) Studies on fatty acid composition of human serum lipids (II). Serum fatty acid composition of inhabitants in a fishing area, Kyoto. Japanese Journal of Hygiene 36, 43-50.

Kannel WB \& Sorlie P (1979) Some health benefits of physical activity. Archives of Internal Medicine 139, 857-861.

Keys A (1970) Coronary heart disease in seven countries. Circulation 41, Suppl. 1, 162-183.

Keys A, Menotti A, Karvonen MJ, Aravanis C, Blackburn H, Buzina R, Djordjevic BS, Dontas AS, Fidanza F, Keys MH, Kromhout D, Nedeljkovic S, Punsar S, Seccareccia F \& Toshima H (1986) The diet and 15-year death rate in the Seven Countries Study. American Journal of Epidemiology 124, 903-915.

Kondo T, Ogawa K, Satake T, Kitazawa M, Taki K \& Sugiyama S (1986) Plasma-free eicosapentaenoic acid/arachidonic acid ratio: a possible new coronary risk factor. Clinical Cardiology 9, 413-416.

Konishi M, Iida M, Naito Y, Terao A, Takayama Y, Ito H, Yutani C, Ito M, Kojima S, Shimamoto T, Inada H, Doi M, Iso H, Sato S, Kitamura A \& Komachi Y (1987) The trend of coronary heart disease and its risk factors based on epidemiological investigations. Japanese Circulation Journal 51, 319-324.

Kuriki K, Nagatani T, Fujiwara N, Sato T, Tokutome Y, Imaeda N, Maki S \& Tokutome N (2000) Relationship between the amount of fat intake for 7 days and serum fatty acid levels. Journal of Epidemiology 10, Suppl. 1, 106 (in Japanese).

Malinow MR, Duell PB, Hess DL, Anderson PH, Kruger WD, Phillipson BE, Gluckman RA, Block PC \& Upson BM (1998) Reduction of plasma homocyst(e)ine levels by breakfast cereal fortified with folic acid in patients with coronary heart disease. New England Journal of Medicine 338, 1009-1015.

Morris JN, Marr JW \& Clayton DG (1977) Diet and heart; A postscript. British Medical Journal 2, 1307-1314.

Okuyama H (2001) High n-6 to n-3 ratio of dietary fatty acids rather than serum cholesterol as a major risk factor for coronary heart disease. European Journal of Lipid Science and Technology 103, 418-422.

Renaud S \& de Lorgeril M (1992) Wine, alcohol, platelets, and the French paradox for coronary heart disease. Lancet 339, $1523-1526$.

Rimm EB, Willett WC, Hu FB, Sampson L, Colditz GA, Manson JE, Hennekens C \& Stampfer MJ (1998) Folate and vitamin B6 from diet and supplements in relation to risk of coronary heart disease among women. Journal of the American Medical Association 279, 359-364.

Shiba T, Urita Y, Takatsuka J, Takeuchi S, Igarashi M, Asada T, Asano T, Kanai A \& Omoto M (1980) Effect of dietary habits on eicosapentaenoic acid and arachidonic acid contents in human plasma. Journal of the Medical Society of Toho University 27, 404-407.

Taylor TG, Gibney MJ \& Morgan TB (1979) Haemostatic function and polyunsaturated fatty acid. Lancet ii, 1378.

Umemura U, Koike K, Iso H, Sankai T, Shimamoto T, Sato S, Iida M, Handa K \& Komachi Y (1993) Population-based comparative study on dietary habits and serum fatty acid compositions. Japanese Journal of Hygiene 48, 939-954 (in Japanese).

Zuijdgeest-van Leeuwen SD, Dagnelie PC, Rietveld T, van den Berg JWO \& Wilson JHP (1999) Incorporation and washout of orally administered n-3 fatty acid ethyl esters in different plasma lipid fractions. British Journal of Nutrition 82, 481-488. 